\title{
Ayuda, hegemonía y poder: EEUU y la configuración de la agenda global del desarrollo
}

\author{
José Antonio Sanahuja', Augusto Delkáder-Palacios²
}

Resumen: Esta contribución examina el papel de EEUU como actor determinante en la definición del desarrollo, las políticas de ayuda externa y el sistema internacional de cooperación al desarrollo tras la II Guerra Mundial. Para ello, analiza los principales hitos históricos que ayudan a entender esa conexión, desde sus orígenes hasta el 11-S y la Agenda 2030 para el Desarrollo Sostenible, como el Plan Marshall, la Foreign Assistance Act, la "Alianza para el Progreso" o la creación del Comité de Ayuda al Desarrollo de la OCDE en 1960. Con esos hitos de la agenda del desarrollo internacional, Estados Unidos ha dado forma a distintas formas de orden internacional hegemónico, desde una configuración bipolar a una globalización en ascenso y posteriormente en crisis. Esta ha dado paso a nuevos actores y dinámicas que finalmente están poniendo en cuestión su centralidad como actor de ese sistema. Es el caso de la cooperación Sur-Sur de los países emergentes, que demanda una agenda y una arquitectura del desarrollo más amplia e inclusiva a través de los Objetivos de Desarrollo Sostenible.

Palabras clave: EEUU; ayuda; orden internacional; crisis de la globalización; desarrollo; securitización, Agenda 2030.

\footnotetext{
${ }^{1}$ Universidad Complutense de Madrid.

${ }^{2}$ Universidad Complutense de Madrid.
} 
Aid, hegemony and power: the USA and the configuration of global developmentaid

Abstract: This contribution examines the dominating role the United States have played in the definition of what constitutes development, in the politics of external aid, and the international system of development cooperation ever since World War II. To do so, it examines the main historical milestones that have helped shape this connection, from its origins all the way up to $9 / 11$ and the Agenda 2030 for Sustainable Development, looking at the Marshall Plan, the Foreign Assistance Act, the 'Alliance for Progress' or the OECD's creation of the Committee for Development Aid in 1960. Through these milestones the USA have given shape to different forms of hegemonic international order, from a bipolar to a rising global configuration, which has ended up in crisis. This has given rise to new actors and dynamics that are finally putting the USA's central role in this system in doubt. This is the case of the South-South cooperation among developing nations, demanding a wider and more inclusive development agenda and architecture through the Sustainable Development Goals.

Key words: USA; aid; international order; crisis of globalisation; development; securitisation, Agenda 2030.

\section{Aide, hégémonie et pouvoir: les États-Unis et la configuration de l'aide mondiale au développement}

Résumé: Cette contribution examine le rôle dominant que les États-Unis ont joué dans la définition de ce qui constitue le développement, dans la politique d'aide extérieure et dans le système international de coopération au développement depuis la Seconde Guerre mondiale. Pour ce faire, elle examine les principaux jalons historiques qui ont contribué à façonner celien, depuis ses origines jusqu'au 11 septembre et à l'Agenda 2030 pour le développement durable, en passant par le plan Marshall, la loi sur l'aide étrangère, |'»Alliance pour le progrès» ou la création du Comité d'aide au développement de l'OCDE en 1960. À travers ces jalons, les États-Unis ont donné forme à différentes constellation $d^{\prime}$ 'ordre international hégémonique, d'une configuration bipolaire à une de caractère mondiale ascendante, qui a fini par entrer en crise. Celle-ci a donné naissance à de nouveaux acteurs et dynamiques qui remettent finalement en question le rôle central des États-Unis dans ce système. C'est le cas de la coopération Sud-Sud entre les nations en développement, qui réclament un programme et une architecture de développement plus larges et plus inclusifs par le biais des objectifs de développement durable.

Mots clé: USA, États-Unis; aide; ordre international; crise de globalisation; développement; titrisation, Agenda 2030.

\section{Introducción}

Durante la segunda mitad del siglo XX Estados Unidos (EEUU) ha sido el actor más determinante para la configuración de la agenda global de desarrollo, como resultado de su posición preeminente en la configuración de los órdenes internacionales hegemónicos que se han sucedido tras la II Guerra Mundial, y en particular el 
sistema bipolar y la globalización neoliberal. En términos de agencia, tanto en el plano bilateral como a través de las instituciones internacionales de desarrollo como el Banco Mundial, el Fondo Monetario Internacional (FMI) o la Organización para la Cooperación y el Desarrollo Económico (OCDE), Estados Unidos ha definido el contenido de la agenda de desarrollo y el significado mismo de este concepto, en términos de su propia experiencia histórica de modernización capitalista. También ha establecido qué políticas e instrumentos han de desplegarse para alcanzarlo en el plano e internacional. En este último, en particular, a través de la ayuda externa, tanto la orientada al desarrollo como la militar y de seguridad. Este artículo presta especial interés a su política de ayuda exterior y especialmente a la considerada Ayuda Oficial al Desarrollo (AOD), por ser Estados Unidos el principal donante mundial de AOD en términos absolutos ${ }^{3}$.

En esa función de agencia, Estados Unidos y su ayuda exterior ha estado conectada con una compleja gama de intereses, no siempre coherentes entre sí: seguridad nacional, en términos de competencia estratégica, equilibrio de poder y contención del comunismo, o lucha contra el narcotráfico o el terrorismo; democratización, dentro de una visión liberal; y expansión de mercados y apertura de los países en desarrollo al comercio y la inversión extranjera.

La actual crisis de la globalización como orden hegemónico, y el relativo repliegue estadounidense es causa y a la vez consecuencia de una amplia contestación o cuestionamiento del orden internacional liberal. Esa contestación se produce al interior de las sociedades $y$ en el plano internacional, con el ascenso de fuerzas nacionalistas que rechazan el multilateralismo o plantean visiones revisionistas, como ocurre con los países emergentes. Dicha contestación se ha extendido diversos campos, incluyendo el desarrollo, también en cuestión a causa del ascenso y entrada en escena de nuevos actores y dinámicas en el sistema internacional de ayuda y cooperación. La agenda del desarrollo es, debido al cuestionamiento del modelo hegemónico, un campo contestado y en disputa en cuanto a los objetivos, los actores y estrategias de desarrollo, en las que Estados Unidos ya no puede jugar el papel dominante de décadas anteriores.

\footnotetext{
${ }^{3}$ Pese a no ser objeto del presente trabajo, un análisis de la ayuda exterior de la URSS en el contexto de la Guerra Fría puede verse en Raffert y Singer (1996).
} 


\section{El nacimiento de la ayuda exterior: seguridad nacional y contención del comunismo}

En este trabajo, siguiendo a Robert Cox (1981) se considera que existe hegemonía cuando la distribución de capacidades materiales, las instituciones y las reglas vigentes, y las ideas dominantes definen una estructura histórica congruente y estable, que, como marco de acción, establece unos márgenes reducidos de actuación, en términos de agencia, para los actores internacionales ${ }^{4}$. Así, hegemonía y orden hegemónico son hechos que se atribuyen a la estructura social e histórica que rige en el plano internacional, y por ende al poder estructural que ahí radica, que a actores estatales y al ejercicio de su poder relacional. Un actor puede tener un rol hegemónico en la medida que conforma esas estructuras históricas, mas que en el ejercicio permanente de su poder relacional. Como estructura de poder, y locus de poder estructural, el sistema bipolar conformó una estructura histórica de carácter hegemónico, en el que EEUU tuvo un papel fundacional y en la que articuló uno de los polos de poder y su correspondiente esfera de influencia. Para ambas superpotencias, la ayuda al desarrollo se configuró como instrumento clave para conformar esa estructura, en términos tanto de recursos materiales como de instituciones e ideas dominantes. Dentro de ella, los países en desarrollo, muchos de ellos en plena descolonización, se vieron situados dentro del conflicto bipolar, en una posición dependiente, o bien fueron objeto de disputa de ambas superpotencias

Desde su origen, en la ayuda exterior de EEUU se observa la preponderancia de los objetivos geoestratégicos, con el desarrollo socioeconómico en un rol subsidiario (Spear, 2016: 18). La etapa inicial de la ayuda exterior de EEUU coincide con las presidencias de Harry S. Truman (1945-1953) y Dwight Eisenhower (1953-1961), y está estrechamente vinculada al papel y objetivos de EEUU dando forma al orden internacional hegemónico que emergió tras la Segunda Guerra Mundial. El Plan Marshall, impulsado entre los años 1947 y 1954 por el secretario de Estado George Marshall reflejó con claridad lo expresado anteriormente. Apoyándose en la idea del vínculo positivo entre desarrollo económico y estabilidad política, el plan buscaba reconstruir una Europa devastada por la guerra. La idea de fondo era promover en el exterior contextos favorables a las motivaciones e intereses militares y económicos de EEUU y, de este modo, reforzar su rol en la construcción de un orden internacional hegemónico.

\footnotetext{
${ }^{4}$ Para una discusión más amplia de la aportación de Cox y del concepto de hegemonía en términos de agencia y estructura, ver también Sanahuja (2019).
} 
Los Estados Unidos deben hacer todo lo que sea posible para asistir al retorno de la salud económica normal en el mundo, sin la cual no habrá estabilidad política ni garantía de paz (Marshall, 1947: 5).

Pero si el Plan Marshall tenía un claro marco europeo, en el plano global la política exterior y de la ayuda internacional de EEUU se definió en la Doctrina Truman y en el Discurso de los Cuatro Puntos, con sus referencias al apoyo a las naciones "amantes de la libertad" y las áreas "subdesarrolladas" (Truman, 1949). Dejando atrás el aislacionismo de entreguerras, ambas iniciativas son inseparables del inicio de la Guerra Fría. Como el Plan Marshall, la Doctrina Truman, de clara impronta realista, estaba presidida por la contención del comunismo a escala mundial (Gaddis, 1982). Como señaló Griffin (1991: 647), "la ayuda externa es un producto de la Guerra Fría, de la división del mundo en el Primer, Segundo y Tercer mundo y de la hostilidad de las superpotencias".

Como indica Gronemeyer (1996: 20), "Truman postuló la obligación de Estados Unidos de ofrecer ayuda financiera y económica más allá de sus fronteras como una contribución al 'Mundo libre', a la estabilidad global y a un desarrollo político ordenado". De esta manera, se expande el criterio geográfico de la ayuda exterior hasta abarcar a todo el mundo en desarrollo no comunista. EEUU utilizaba así la ayuda exterior como un medio para "mantener el comunismo acorralado y bajo control" (Spear, 2016: 19).

Sin embargo, en esta etapa inicial la ayuda exterior se concibe más como un mecanismo de cooptación o de estabilización de gobiernos afines, y no aparece vinculada al desarrollo socioeconómico, una cuestión para la que en los años cincuenta no existía tan siquiera una mínima teorización en la economía o la sociología. Así se estableció expresamente en los primeros instrumentos legales para otorgar ayuda al amparo del "punto cuatro" más allá de los confines europeos del Plan Marshall. Es el caso de la denominada "Ley de Seguridad Mutua" (Mutual Security Act) aprobada en 1951 y en vigor hasta 1960, y su precedente, la Ley de Asistencia para la Defensa Mutua de 1949, que no mencionaban ni una sola vez el desarrollo socioeconómico y combinaban ayuda tanto económica como militar. A cambio, afirmaban como objetivos expresos de la ayuda el apoyo a los "gobiernos amigos" en la contención del comunismo, y ser una contraprestación al establecimiento de bases militares en el "cinturón de defensa perimetral" que, al servicio de la contención, se estableció en torno a la Unión Soviética y sus aliados, incluyendo en ese momento a la China surgida del triunfo comunista en 1949. En 1954, con la aprobación de la ley PL-480 sobre ayuda alimentaria, EEUU mantuvo esos objetivos estratégicos y de contención del comunismo, pero añadió 
una motivación económica a la hora de dar salida a sus excedentes agrícolas: ampliar mercados para sus exportaciones en ese sector.

El legado de esta etapa fundacional y del papel de EEUU aún perdura en el sistema internacional de ayuda al desarrollo en cuanto a recursos, normas e ideas dominantes. En términos materiales, el Plan Marshall y la ayuda otorgada en Europa y Asia, supuso una enorme movilización de recursos, que no ha vuelto a repetirse, y fue clave en la conformación del sistema bipolar y el relanzamiento económico de ambas regiones frente al bloque comunista. En términos de normas e instituciones, se asentó la primacía de la ayuda bilateral, su naturaleza voluntaria y discrecional, y su vinculación axiomática con los intereses del donante, en particular con intereses estratégicos, con un papel limitado de los organismos multilaterales, como el Banco Mundial o Naciones Unidas. Estos últimos, aun siendo también creación de EEUU, quedaron situados en una posición marginal y subsidiaria respecto a las lógicas de mercado en cuanto a la financiación del desarrollo, conforme a la visión liberal con la que EEUU articuló las finanzas internacionales de posguerra.

En términos de las ideas también conviene destacar el papel del programa del punto cuatro del discurso del presidente Truman, por su influencia en la aparición de la noción misma del desarrollo, "adquiriendo una suerte de legitimidad universal" (Valcárcel, 2006: 5) y la aparición de lo que algunos autores denominan "la era del desarrollo". Aunque la teoría del desarrollo aparece años después, ese concepto se convirtió en un poderoso dispositivo discursivo e ideacional, en el sentido foucaultiano del término, que subordinaría los horizontes cognitivos de los países pobres y en proceso de descolonización a un imaginario occidental de progreso $y$, en lo referido al bloque occidental, al proceso de modernización capitalista ${ }^{5}$ (Sachs, 1996; Escobar, 1995). Siguiendo a Rist (2002), el desarrollo redefinió el principio de jerarquía civilizatoria al considerar que los países subdesarrollados estaban atrasados y solo podían desarrollarse emulando los patrones occidentales. De algún modo, la modernización denominó subdesarrollados a los países que el imperialismo y el colonialismo nombró antes como bárbaros o primitivos. De hecho, Truman acuñó por primera vez el término "áreas subdesarrolladas", como alternativa al término "regiones económicamente atrasadas", antes utilizado por el economista "pionero" del desarrollo Paul Rosenstein-Rodan (1944).

\footnotetext{
${ }^{5}$ Más adelante, haremos referencia a otras visiones del desarrollo posteriores como la teoría de la dependencia (Cardoso y Faletto, 1971), el enfoque de necesidades básicas (Streeten, 1986), el enfoque de las capacidades (Sen, 1989), el desarrollo humano (Griffin y McKinley, 1994) o el post-desarrollo (Rist, 2002; Escobar, 1995; Esteva, 1996; Sachs, 1996 o Hettne y Blomström, 1990).
} 


\section{La Administración Kennedy y el desarrollismo contrainsurgente}

Las aspiraciones de emancipación y progreso que trajo consigo el proceso de descolonización, unidas a la aparición de la teoría del desarrollo, llevaron a que a que Naciones Unidas proclamara en los años sesenta la primera "década del desarrollo". Pero el desarrollo va a ser desde el inicio un concepto y uan práctica en disputa. Si ya en los años cincuenta emerge el enfoque latinoamericano de la dependencia, también lo hace, como paradigma dominante, la idea de modernización a partir de las ideas sociológicas de Parsons, y de la economía del desarrollo de autores como Arthur Lewis, Paul Rosenstein-Rodan y, sobre todo, W. W. Rostow y su visión del "desarrollo por etapas" desde la sociedad tradicional a la sociedad de consumo de masas conforme al modelo de EEUU. Para este autor, cuya obra de referencia tiene el significativo título de The stages of economic growth. A non-comunist manifiesto, el desarrollo como modernización económica fue entendido en términos de crecimiento económico a partir de la combinación de capitalismo y democracia, en clave anticomunista. En este marco, surgen las primeras teorías económicas de la ayuda externa, entendida, en clave keynesiana, como vía para suplir las carencias de ahorro interno y capital y hacer frente a las fallas de mercado y brechas de inversión presentes en los países pobres (Chenery y Strout, 1966; Sanahuja, 1999: 24).

La presidencia de John F. Kennedy (1961-1963) representa un nuevo momento fundacional para el sistema internacional de ayuda y cooperación cuyo legado aún perdura. Kennedy, muy influido por la naciente economía del desarrollo, dejó atrás la estrategia de la contención y pretendió asumir el liderazgo del "mundo libre". La breve presidencia de Kennedy representa un segundo momento fundacional en el sistema internacional de cooperación y ayuda al desarrollo: se aprobó la Ley de Asistencia Exterior de 1961, que aun con muchas enmiendas siguió estando en vigor hasta entrado el siglo XXI. Se creó la Agencia para el Desarrollo Internacional de los Estados Unidos (USAID), se reformó la ayuda alimentaria, con la nueva denominación de "Alimentos para la Paz", y se puso en marcha el "Cuerpo de Paz", con jóvenes voluntarios. También hubo cambios importantes en la cooperación multilateral, en algunos casos planteados por la administración Eisenhower como respuesta a la revolución cubana, como la creación del Banco Interamericano de Desarrollo -una vieja demanda latinoamericana-, la creación del Comité de Ayuda al Desarrollo (CAD) de la OCDE, como mecanismo para alinear en una estrategia común a otros donantes occidentales cuya ayuda estaba ligada a lógicas poscoloniales; o la aparición, también en 1960 de la ventanilla "blanda" del Banco Mundial como respuesta al reclamo de financiación "blanda" de los países en desarrollo a través de Naciones Unidas. Son estas iniciativas, 
bilaterales y multilaterales, con las que realmente aparece lo que hoy se entiende por ayuda al desarrollo, pues hasta ese momento e lacceso a recursos extenos por parte de los países pobres se realizaba o bien en términos de mercado, a través del banco mundial, o bien con una explícita motivación estratégica ligada a la competencia bipolar.

Todo lo anterior suponía un claro rechazo a la estrategia de la contención, cuya lógica militarizada era, según Kennedy y sus asesores, entre los que se encontraba el propio Rostow, ineficaz y contraproducente, como parecían demostrar hechos como la revolución cubana, en pleno "patio trasero" de EEUU. Frente a ello, se debería promover el desarrollo y la ayuda exterior como vía más eficaz para contener el comunismo y asegurar el liderazgo de EEUU. Ese desarrollismo puede ser visto como una nueva estrategia de contención de signo liberal (liberal containment) (Packenham, 1973). El propio Rostow consideraba que el desarrollo del Tercer Mundo era uno de los escenarios principales de la competencia del mundo bipolar, y su teoría proporcionó una justificación económica y política convincente para la ayuda como herramienta tanto de la política exterior como de la economía del desarrollo" (Sanahuja, 1999: 22-25).

Sin embargo, esta relación positiva entre desarrollo económico, estabilidad política e interés nacional de EEUU iba a ser cuestionada por los autores del realismo políitico. El propio Hans Morgenthau, en un texto ya clásico, criticaba a los economistas del desarrollo y sus aspiraciones de cambio, ya que comportaban riesgos de inestabilidad que deberían evitarse. Ello limitaría los usos de la ayuda extena a la tradicional búsqueda de estabilidad y a comprar voluntades en otros gobiernos (Morgenthau, 1961).

Quizás la plasmación más visible de esa estrategia fue la Alianza para el Progreso, lanzada en 1961 por Kennedy como respuesta reformista al riesgo de "contagio" de la revolución cubana. Crecimiento económico, modernización del Estado y reforma social-incluyendo la reforma agraria-fueron sus ejes (Sanahuja, 2011 : 198). Pero la Alianza fue un fracaso ante la resistencia al cambio de las élites en América Latina, al verse privada de recursos por parte de EEUU, cada vez más centrado en la guerra de Vietnam ${ }^{6}$, y desviada de sus objetivos de democracia y reforma por la administración Johnson, que prefirió apoyar gobiernos militares y "regímenes de seguridad nacional" (Levinson y Onís, 1972). El ciclo insurreccional

${ }^{6}$ En el Anexo I se reflejan los montos de AOD que EEUU entregó a Vietnam, siendo el segundo receptor global en los años sesenta y setenta con más de 30.000 millones de dólares. 
de los años setenta en áreas como Centroamérica se explica en parte por estos hechos (Lafeber, 1989).

Mención especial requiere también la construcción de las que aún hoy sigue siendo una de las principales estructuras internacionales de gobernanza de la ayuda. Es el caso del CAD, como instancia especializada de la OCDE, creada en $1961^{7}$ a instancias de EEUU, en lo que puede interpretarse como una forma de implicar a los socios de EEUU en el burden sharing de la ayuda al Tercer Mundo y ese esfuerzo de contención liberal (Sanahuja, 1999: 26). En efecto, la OCDE se convirtió en la principal instancia de orientación estratégica y regulación de la ayuda al desarrollo (Lumsdaine, 1993).

Se debe resaltar que el enfoque del desarrollo como modernización capitalista y los principios liberales subyacentes a la regulación internacional del comercio y las finanzas internacionales tuvieron una contestación destacada desde la teoría de la dependencia. Este enfoque asume que las causas del subdesarrollo se encuentran en una estructura económica y política de dominación centro-periferia, quedando las economías de la periferia relegadas a la mera exportación de materias primas (Cardoso y Faletto, 1971). Por ello, reclaman vías nacionales de desarrollo mediante la industrialización por sustitución de importaciones, y una reordenación del sistema financiero y el comerco internacional favorable al desarrollo. Esta mirada pensó el desarrollo desde el sur y tuvo un efecto directo en las orientaciones políticas de la Comisión Económica para América Latina y el Caribe de las Naciones Unidas (CEPAL), con el liderazgo de economistas como Raúl Prebisch, y en la convocatoria de las primeras Conferencias de Naciones Unidas sobre Comercio y Desarrollo (UNCTAD) en 1964 y 1968, y en la propuesta de un Nuevo Orden Económico Internacional (NOEI), adoptada por la Asamblea General de Naciones Unidas en 1974. Todo ello, impulsado por el Movimiento de los Países No Alineados, surgido tras la Conferencia de Bandung (1955), y del G77, creado en la I UNCTAD en 1964. Aunque estas iniciativas, resistidas por EEUU y sus aliados occidentales, no lograron conformar una alternativa a las normas, instituciones y enfoques dominantes, sí lograron forzar reformas importantes como la propia aparición de la ayuda concesional a partir de 1960, o mejoras en el acceso a los mercados de los países ricos a través de sistemas de preferencias comerciales más abiertos.

${ }^{7}$ La OCDE sustituyó a la Organización Europea para la Cooperación Económica (OECE), creada en 1948 para gestionar las ayudas del Plan Marshall. 


\section{Modernización sin reforma, neoliberalismo y "segunda Guerra Fría" en la Administración Reagan}

En década de los setenta la política exterior de EEUU y, por extensión, la política de ayuda fueron objeto de un serio replanteamiento como consecuencia de un escenario internacional cambiante que ponía en entredicho la hegemonía norteamericana. El trauma generado por la derrota de EEUU en Vietnam, así como la crisis del petróleo y la emergencia de nuevos actores forzaron la revisión del papel de EEUU en el mundo (Sanahuja, 1999: 36). Frente al realismo político, ganó peso el enfoque transnacional de la interdependencia (Keohane y Nye, 1977) y se aceptó la necesidad de la cooperación para el mantenimiento de una hegemonía en declive, lo que se tradujo en una apuesta por el multilateralismo.

Esta reorientación influyó en la ayuda exterior de EEUU, que fue objeto de un doble cuestionamiento. Por un lado, el desarrollismo anticomunista de Rostow fue contestado porque no era capaz de contribuir ni al desarrollo ni a la estabilidad política. Por otro, se entendió también fracasada la estrategia de reducción de la pobreza centrada exclusivamente en el crecimiento económico, propuesta por el enfoque de la modernización. Frente a esta modernización excluyente o de crecimiento con pobreza, surgió en esta segunda década del desarrollo el enfoque de las necesidades básicas (Streeten, 1986). Lo que se planteaba era la urgencia de dar un giro social a la modernización incluyendo en la agenda, entre otras, la distribución de la riqueza y la distinción entre crecimiento y desarrollo (Riddell, 1987). A esta misma línea apuntó el influyente Informe Pearson, a cargo del Banco Mundial (Pearson, 1969). Además, el contexto de la distensión entre las superpotencias era propicio para esa revisión al dejar mayor espacio a objetivos no estrictamente geopolíticos en la asignación de la ayuda (Spear, 2016: 20). La presidencia de Jimmy Carter (1977-1981) rebajó la dimensión de seguridad en la ayuda exterior, con un mayor énfasis en la promoción del desarrollo, la democracia y los derechos humanos. Quizás el caso más visible es el del Banco Mundial en el periodo 1968-1981, bajo la presidencia de Robert McNamara, anterior secretario de defensa de EEUU con Kennedy y Johnnson y uno de los artífices la guerra de Vietnam. Ese periodo supuso un fuerte aumento de los recursos y los créditos del Banco, que por primera vez asumía como objetivo expreso la lucha contra la pobreza (Sanahuja, 2001: 70-81). El denominado "enfoque McNamara" seguía concibiendo la pobreza como caldo de cultivo para la explosión revolucionaria y el comunismo, abogando por un nuevo esfuerzo de modernización vía crecimiento económico. Este enfoque, sin embargo, dejó un costoso legado en los países en desarrollo en cuanto a polarización socioeconómica, empeoramiento de la seguridad alimentaria, al promover cultivos para la exportación, deterioro ambiental, 
fuerte endeudamiento -preludio de la crisis de la deuda de 1982 en adelante-, y politización de esta institución. Este nuevo ciclo desarrollista, más centrado en la pobreza, no significó que las prioridades estratégicas y de seguridad no siguieran estando presentes, aunque cambiasen sus prioridades geográficas, centradas en Oriente Próximo tras la derrota de Vietnam. En particular, tras los Acuerdos de Camp David de 1979, en los que Estados Unidos recurrió de manear indisimulada a la "diplomacia de chequera" con abultados compromisos de ayuda económica y militar, Israel y Egipto, por ese orden, pasaron a ser los primeros receptores de la ayuda exterior de EEUU en todo el mundo ${ }^{8}$, situación que iba a mantenerse durante los años ochenta y noventa (Sanahuja, 1999: 39-42; 2001 b: 65; OCDE, 2021 a).

Durante los años ochenta, además de caracterizarse por un marcado acento multilateral, la ayuda exterior se insertó en un ciclo de políticas de estabilización y ajuste lideradas por las instituciones de Bretton Woods: el Banco Mundial y el FMI. Inicialmente, estas políticas se formularon para que las economías latinoamericanas pudieran hacer frente a la crisis de deuda iniciada en 1982. Sin embargo, siguieron aplicándose hasta bien entrados los años noventa, como parte de una estrategia neoliberal de inserción de los países en desarrollo en los procesos de globalización vía la apertura de sus economías al comercio y la inversión extranjera. De hecho, más de un centenera de países adoptaron esas políticas de apertura, que en muchos casos suponían abandonar las políticas de industrialización de las décadas anteriores (Sanahuja, 2001a; 2011: 199). Esto supuso un claro alejamiento del desarrollismo anterior y la entrada en escena del conocido como "Consenso de Washington" (Williamson, 1990), un programa de economía política centrado en la apertura económica al exterior y la disciplina presupuestaria, con poca atención a la cohesión social. El rol de EEUU fue determinante, pues tanto el FMI como el Banco Mundial asumieron formalmente las políticas de dicho Consenso, y se alinearon con la visión neoliberal que asumió Washington con la llegada a la presidencia de Ronald Reagan en 1981.

La presidencia de Ronald Reagan (1981-1989) significó, vía crisis de la deuda y ajuste estructural, una amplia derrota y abandono del reformismo desarrollista del G77 y de las propuestas del NOEl. Pero también se produjo un claro giro de política exterior hacia posiciones neorrealistas que rechazaban el liberal containment y abrían una "segunda Guerra Fría". La propuesta de Reagan para recuperar la hegemonía estadounidense era un retorno a las estrategias duras de seguridad nacional (neocontención) y al restablecimiento del libre mercado en el

${ }^{8}$ Los montos específicos se detallan en el Anexo I. 
orden económico internacional (neoliberalismo) (Bello et al., 1994). En ese marco, la ayuda se insertaba en dos lógicas, que en no pocos casos eran contradictorias. Por un lado, en la agenda económica neoliberal, donde la financiación externa, en particular la otorgada vía instituciones financieras multilaterales, se condicionaba a las reformas de política de los receptores que facilitasen su inserción en la economía internacional como economías primario-exportadoras, dando fin al proteccionismo y al nacionalismo desarrollista. Esto último se implementó, en particular, con los programas de ajuste del Banco Mundial y el FMl y sus estrategias de "condicionalidad cruzada" (Griffith-Jones, 1988). Por otro lado, en la agenda de la seguridad nacional y el anticomunismo, otorgando ayuda para estabilizar gobiernos y evitando así, como ocurrió en Centroamérica, los programas de ajuste del FMl y el Banco Mundial y sus potenciales efectos desestabilizadores. También se empleó, en ocasiones, para financiar grupos armados irregulares que intentaban derrocar gobiernos comunistas o que no se subordinaban a los intereses de EEUU, o apoyar a los gobiernos que les daban cobertura. Con todo ello, la ayuda exterior se instrumentalizó y subordinó, de forma mucho más directa si cabe, a los objetivos geoestratégicos de EEUU en el contexto de las políticas de poder de la "segunda" Guerra Fría (Halliday, 1983, Sanahuja, 1999).

\section{La redefinición de la seguridad nacional: la ayuda en el con- texto de la posguerra fría}

El fin de la Guerra Fría trajo consigo una reconfiguración del orden mundial. El colapso de la Unión Soviética y la arrolladora victoria de EEUU en la Guerra del Golfo pareció anunciar una etapa de unipolaridad sin rivales, pero con la administración Clinton Estados Unidos inició una etapa de repliegue y tendencias aislacionistas, y la dinámica más relevante fue, sin embargo, la conformación de la globalización como una nueva estructura histórica de carácter hegemónico, caracterizada, en el ámbito de las capacidades materiales, por la transnacionalización productiva, un mayor grado de interdependencia y un visible proceso de difusión del poder a través de empresas multinacionales y países emergentes. En el ámbito de las instituciones, por la "constitucionalización externa" de la apertura económica vía los acuerdos de la Organización Mundial de Comercio (OMC), en particular el Acuerdo de Marraquech (1995) y la oleada de acuerdos regionales de comercio y de acuerdos de protección de inversiones de este periodo. Y, en el ámbito de las ideas, por el marco ideológico que emerge con la posguerra fría: el del capitalismo globalizado y la democracia liberal como teleología de progreso y únicos modelos políticos y económicos viables, que se resumió en la tesis del "fin de 
la historia" de Francis Fukuyama. De este modo, se impusieron las tesis de que las democracias de mercado eran el mejor camino para avanzar en términos de paz, seguridad y desarrollo, en una especie de relación virtuosa. Por tanto, la agenda de la seguridad y el desarrollo giraron en torno a la promoción de la democracia y el libre mercado. En el caso de EEUU se orientó a aquellos escenarios en las que esas cuestiones eran más relevantes, con propuestas como el Proyecto Democracia y la Iniciativa para las Américas (Sanahuja, 1999: 71; Lake, 1993). De acuerdo con la tesis de la paz liberal, la idea subyacente era que las democracias tienen políticas exteriores más pacíficas, con lo que el entorno internacional sería más estable y funcional a los intereses de EEUU (Christopher, 1995).

Desaparecidas las motivaciones estratégicas que en realidad explicaban parte de los flujos de ayuda externa, una de las primeras consecuencias del fin de la Guerra Fría fue la significativa reducción de la AOD global, que descendió en torno a un 30\% (OCDE, 2021 a y 2021 b; Severino y Ray, 2009). También se produjeron cambios importantes en la pauta de asignación geográfica de la ayuda. Se redujeron las partidas a receptores clásicos de África y Asia, en favor de los "países en transición" hacia el mercado -una nueva categoría de receptores definida por el CAD- de Europa oriental y el anterior espacio soviético (Rosner 2012). Sin embargo, Oriente Próximo y algunos países de América Latina continuaron siendo importantes receptores de ayuda por razones estratégicas y de seguridad nacional (Spear, 2016: 20). En esta región, Centroamérica fue objeto de la "devaluación estratégica" que muchos países sufrieron al terminar la Guerra Fría, mientras que el narcotráfico, que pasó a ser visto con un prisma securitario, hizo de los países andinos y en particular de Colombia el principal receptor de ayuda en esa región por parte de Estados Unidos y de otros donantes. En este contexto, destaca la Iniciativa Andina (1989) y el posterior "Plan Colombia" (1999), que incluían ayuda militar y económica, y amplias preferencias comerciales, sujetas a un proceso de "certificación" y a una estricta condicionalidad unilateral antinarcóticos por parte de EEUU. Ello muestra que durante las presidencias de George Bush (1989-1993) y Bill Clinton (1993-2001) la ayuda exterior continuó estando ligada a la seguridad, aun considerando como nuevas amenazas el narcotráfico o el terrorismo.

Desaparecidos los imperativos estratégicos de la Guerra Fría, y confiado el proceso de desarrollo socioeconómico y de reducción de la pobreza a las fuerzas de la globalización, no parecía haber una racionalidad robusta para la ayuda externa y la cooperación para el desarrollo. Por otro lado, el repliegue de la Administración Clinton redujo el rol de EEUU como actor dominante en la agenda del desarrollo. Con todo ello, el desarrollo se desecuritizó y se repolitizó en un proceso en el que adquirió un valor propio en vez de ser un mero instrumento de políticas de 
seguridad (Sanahuja y Schünemann, 2012: 24). Ello permitió que otros actores, como Naciones Unidas o las redes de ONG internacionales, de creciente influencia, promovieran una agenda crítica a la globalización a través de las "cumbres" sociales de este periodo, y que irrumpieran nuevos enfoques y agendas para la gobernanza global del desarrollo. A ello contribuyó la evidencia de que las políticas del Consenso de Washington y la apertura a las dinámicas de la globalización no lograban reducir la pobreza, y se agudizaba la desigualdad. Por un lado, el enfoque de las capacidades comienza a plantear que el referente del desarrollo son los seres humanos y no el crecimiento económico y, más en concreto, la expansión de las capacidades humanas para realizar actividades libremente (Sen, 1989). Por otro, el concepto desarrollo humano se da a conocer con el primer informe de Desarrollo Humano del PNUD. Desde esta visión, el desarrollo se entiende como un proceso de ampliación de las oportunidades de las personas, destacando la salud, la educación y las libertades políticas (PNUD, 1990). Estas aproximaciones al desarrollo pusieron el foco en el bienestar humano, abandonando la mirada economicista de la modernización. Tuvieron un impacto muy destacado no solo en el plano teórico, sino también en las prácticas de las políticas de ayuda de actores emergentes en el sistema de ayuda. Son esos nuevos actores e ideas los que en buena medida explican que en 2000 se adoptara la Declaración y los Objetivos de Desarrollo del Milenio (ODM), a modo de "agenda social" de una globalización neoliberal contestada.

\section{El II-S y la Guerra Global contra el Terrorismo: securiti- zación y desvío de la ayuda}

El impulso de los ODM, sin embargo, fue de corto aliento. Con los atentados del 11 de septiembre de 2001 EEUU despliega una nueva matriz de política exterior y de seguridad de orientación neoconservadora, la denominada "Guerra Global Contra el Terror" (GGCT), que supone un mayor intervencionismo y un proceso a gran escala de securitización (Messina, 2014), en el sentido que le dan a este concepto los estudios críticos de seguridad: esto es, el proceso por el que un actor securitizador afirma mediante un acto discursivo la presencia de una amenaza existencial, lo que le otorga poder y legitimidad para desplegar medidas extraordinarias (Waever, et al., 1998).

Todo ello ha generado un amplio debate sobre la securitización de la ayuda al desarrollo, que supone cambios discursivos, institucionales, y materiales (Harbone, 2012); Sanahuja y Schünemann, 2012; y Brown y Grävingholt, 2016). Pueden 
identificarse al respecto seis tendencias del proceso de securitización de la ayuda al desarrollo al calor de la GGCT (Sanahuja y Schünemann, 2012: 28-32). Primero, las narrativas y la retórica volvieron a justificar la ayuda exterior por razones de seguridad nacional y no de desarrollo. En su versión más dura, los "halcones" republicanos y neocon la vieron como mera herramienta de estabilización tras las intervenciones militares de la GGCT, mientras que las "palomas" demócratas pasaron a verla como mecanismo de prevención del terrorismo, afirmando que terrorismo, pobreza y desarrollo están relacionados. Segundo, las agendas multilaterales de consolidación de la paz y seguridad humana se redefinieron en ese mismo sentido, quedando en muchos casos subordinadas a los imperativos de la GGCT. Tercero, se produjo una movilización extraordinaria de recursos: a escala global, la AOD llegó a triplicarse entre 2001 y 2010. En el caso de EEUU se incremento más del doble, como puede observarse en el anexo II, sobre todo a través de la ayuda bilateral, como se observa en el Anexo III. Es muy destacable que la ayuda gestionada por el Pentágono pasase del 5,6\% al $21 \%$ entre 2002 y 2005. Cuarto, se observaron cambios relevantes en la asignación geográfica de la ayuda, priorizando países clave de la GGCT y no para el cumplimiento de los ODM. Prueba de ello es que la mayor parte de la AOD mundial, y en particular la de EEUU, se asignó a Irak y Afganistán, que hasta 2000 apenas recibían ayuda. En 2005 ambos países representaban un tercio del total de la AOD estadounidense, y entre 2000 y 2009 ocuparon los dos primeros lugares. A esto hay que sumar la reorientación de fondos a programas de cooperación cívico-militar que aun computando como AOD son parte de la contrainsurgencia y lucha antiterrorista. Quinto, la securitización del sector de la gobernanza democrática, cada vez más centrado en programas de Desarme, Desmovilización y Reintegración (DDR) y de Reforma del Sector de la Seguridad (SSR), dejando de lado la agenda de la democracia y los derechos humanos. Sexto, destaca una redefinición de las dimensiones del desarrollo en clave de amenaza para la seguridad, como la pobreza, el medio ambiente o las migraciones. No menos importante fueron los cambios institucionales ligados tanto a la securitización como a la militarización de la ayuda. El Departamento de Defensa llegó a ser el principal implementador de programas de ayuda sobre el terreno, en detrimento de una cada vez más debilitada USAID, que en clara desventaja con el Pentágono se adentró en la agenda de la seguridad para mantener recursos e influencia de las denominadas "3D" (diplomacia, defensa y desarrollo) (Spear, 2016: 37).

En conclusión, durante la primera década del nuevo milenio, EEUU mostró una mayor capacidad de agencia para redefinir la agenda del desarrollo en clave de securitización, buscando aprovechar la 'ventana de oportunidad' que le brindaron los atentados del 11-S para reconstruir un orden internacional hegemónico. 
Como proceso de securitización la GGCT significó la (re)definición y priorización de las amenazas y las respuestas políticas a las mismas, incluyendo las políticas de ayuda, cooperación y desarrollo internacional, que se redefinieron en clave antiterrorista. Sin embargo, no debe olvidarse con la GGCT los neocon al frente de la Administración Bush no solo pretendían combatir el terrorismo internacional, ya que el 11-S fue visto como una ventana de oportunidad para desplegar "un nuevo siglo americano"; esto es, reafirmar la primacía de EEUU y su acción unilateral como soporte de un orden mundial hegemónico (Sanahuja y Schünemann, 2012: 27). Aunque la GGCT tuvo un cierto efecto de arrastre en los aliados de EEUU, también suscitó reacciones contrarias en otros actores, como la UE o los países emergentes. Sin embargo, este proyecto se revelaría como una quimera, por partir de una deficiente lectura de la nueva realidad del poder y la interdependencia en un mundo ya intensamente globalizado, con nuevos actores emergentes, y con nuevos retos de desarrollo y gobernanza global que harían inviable cualquier pretensión hegemónica unilateral como la que suponía la GGCT, que a la postre no produjo ni desarrollo ni seguridad, y más bien, erosionó el liderazgo estadounidense a la hora de definir nuevas agendas de desarrollo más amplias, inclusivas y con capacidad de responder a los retos globales del Siglo XXI.

\section{Globalización, hegemonía y cambio estructural: EEUU, los países emergentes y el multilateralismo de los ODM y los ODS}

Se ha hecho ya referencia a que la naturaleza y las características del sistema internacional de cooperación y ayuda al desarrollo son el reflejo de la estructura de la sociedad internacional y de sus dinámicas históricas. Como se ha indicado, el sistema de ayuda se configuró bajo el doble condicionante del conflicto EsteOeste y de las dinámicas Norte-Sur de la descolonización y el decisivo papel de Estados Unidos, en términos de agencia, en su conformación. Con la posguerra fría, el proceso de globalización neoliberal, también con un papel clave de EEUU, define una nueva estructura histórica de carácter hegemónico que redefine el sistema internacional de cooperación al desarrollo, en el que cabe identificar varias dinámicas de cambio.

Por un lado, la sociedad internacional es estadocéntrica $y$, como el sistema internacional de cooperación al desarrollo, sigue teniendo un carácter marcadamente westfaliano, que el orden bipolar no cuestionó. Como se indicó, ello se traduce en la preeminencia de la ayuda bilateral y su carácter voluntario y discrecional, con unos niveles de autonomía de los donantes que permite poner en duda si 
realmente se trata o no de un sistema. Como consecuencia, no hay criterios vinculantes que regulen la asignación de la ayuda en función de metas de desarrollo y, con la excepción parcial de la UE y sus Estados miembros, es difícil promover la coordinación de las intervenciones de los actores. Ahora bien, las dinámicas de transnacionalización, integración económica global, interdependencia, demanda de bienes públicos globales crecientes riesgos transnacionales (crisis financieras, cambio climático, pandemias) llevan varias décadas poniendo en entredicho la viabilidad de esa lógica westfaliana (Sanahuja, 2016). Ello se suma a una visible difusión del poder y creciente influencia de actores no estatales como las ONG, las organizaciones internacionales, la sociedad civil o las corporaciones. Rosenau (1991) lo define como un sistema multicéntrico, en referencia a la pluralidad de actores y a la red de interacciones transnacionales de los mismos. Precisamente, la interdependencia como rasgo clave de la globalización ha puesto en el centro la discusión la cuestión de los Bienes Públicos Globales y ha evidenciado la incapacidad del Estado para suministrarlos y mantenerlos. Así, ha abierto un espacio amplio para actores no estatales como las ONG, las empresas transnacionales y la sociedad civil. Es destacable la transnacionalización de los movimientos sociales y la contestación, cuestión definida con acierto por Kaldor (2005) al referirse a la 'sociedad civil global'.

Por otro lado, el sistema de cooperación es parte de un orden hegemónico y jerarquizado. En términos de poder estructural, define posiciones, condicionantes y opciones diferenciadas para los actores y su agencia, con grandes asimetrías geográficas (brecha Norte-Sur) y entre actores (brechas entre Estados, y entre estos y los actores no estatales). La posición subordinada de los países en desarrollo responde a factores materiales, institucionales e ideacionales, y, con relación a estas últimas, a una visión Occidental de progreso ya la aproximación neoliberal a la economía política global. El mismo concepto de desarrollo pude ser visto como parte de un dispositivo ideacional de la hegemonía Occidental. Pese a la retórica del partnership, sigue presente la condicionalidad. Sin embargo, el proceso de difusión y redistribución del poder que trae consigo la globalización y la crisis que arrastra desde 2008 ha resquebrajado esa estructura, en términos de legitimidad y eficacia, y hace emerger nuevos actores, con mayores opciones en términos de agencia. Estados Unidos y, en general, Occidente industrializado pierde capacidad para seguir definiendo las reglas del sistema, al tiempo que, como se ha indicado, éste se torna obsoleto y disfuncional para hacer frente a los retos de una globalización muy avanzada, pero también en crisis.

Lo anterior no quiere decir que la ayuda al desarrollo no esté institucionalizada y regulada. Pese a su descentralización, no es un sistema anárquico. Existen normas 
y consensos que han llevado a algunos autores a hablar de un régimen internacional de la ayuda (Furia 2015). Como se ha mencionado, dicho entramado de instituciones y normas se ha articulado en al CAD de la OCDE, en el que Estados Unidos tuvo un papel fundacional $y$, junto con un reducido número de donantes del Occidente industrializado ha mantenido una fuerte influencia. Sin embargo, los procesos de cambio de poder generados por un proceso de globalización que se ha extendido por varias décadas lo ponen en cuestión. En lo que se refiere a los actores y recursos, el creciente papel de los actores privados en la financiación del desarrollo y el ascenso de los países emergentes y la cooperación Sur-Sur (CSS) suponen una claro contestación de la representatividad, legitimidad y eficacia de ese selecto club de donantes que es el CAD, así como del Banco Mundial y otras instituciones de financiación del desarrollo, y de sus principios, normas e instituciones reguladoras (Bergamaschi y Tickner, 2017; Esteves y Klingebiel 2021). Los actores de la CSS y los actores privados están desarrollando normas propias que se ajustan mejor a sus requisitos y valores (Fourie et al., 2019), y cabe mencionar también el papel destacado de China como donante y su liderazgo en la creación de nuevas instituciones como el Nuevo Banco de Desarrollo de los BRIC o el Banco Asiático de Inversiones en Infraestructuras.

En definitiva, se han ampliado y fragmentado las normas y las instituciones en el régimen de la ayuda, y también aparecen nuevos espacios para su reformulación más allá del $C A D$, con la aspiración de ser más inclusivos y legítimos. El más significativo ha sido, quizás. El Grupo de Trabajo Abierto que definió la Agenda 2030 de Desarrollo Sostenible antes de su presentación en la Asamblea General de Naciones Unidas en septiembre de 2015 (Sanahuja 2016). También puede mencionarse el Foro Político de Alto Nivel creado como espacio preferente para discutir la agenda del desarrolloy, en concreto, el seguimiento de los ODS. A priori, este último es un espacio multilateral de cooperación horizontal entre socios. Ahora bien, otros muchos espacios compiten en la definición y diseño de la ayuda, con grupos de gobierno como el G20, el grupo de los BRICS, IBSA o MIKTA.

Finalmente, en lo que a las narrativas se refiere existen, al menos, dos corrientes mutuamente contestadas ante los nuevos o más intensos retos de la globalización, como el cambio climático, las migraciones o, desde 2020, la pandemia del COVID-19. Por una parte, se observa un giro discursivo y en las prácticas de la cooperación al desarrollo por el que vuelve a insistir en su en los intereses inmediatos de carácter estratñegico, e seguridad o de índole económica ade los donantes (Mawdsley, 2012; Mawdsley et al., 2018), en el que nuevos donantes, como China, parecen encontrarse muy cómodos. Ello debe enmarcarse en el proceso más amplio de ascenso de visiones iliberales, nacionalistas y de cuestionamiento 
del orden liberal internacional que se observa tanto en los países avanzados como en los emergentes. EEUU, bajo la Administración Trump ha sido uno de los actores prominentes en este sentido. Por otro, la Agenda 2030 ha emergido con fuerza como marco global de referencia en el campo del desarrollo, logrando un alcance y un consenso superior a su predecesora, la Declaración del Milenio y los ODM. Ahora bien, ese mayor consenso no ha modificado el carácter fragmentado e incoherente de la ayuda. Es un espacio en el que se manifiestan luchas por el poder y contestaciones no resueltas (McNeill, 2019), en gran medida porque ha dado espacio a nuevas normas, instituciones y actores (Chaturvedi et al., 2021).

\section{Conclusiones}

En una globalización en crisis, y un orden internacional liberal cuestionado, EEUU es un actor aún relevante, pero frente a nuevos actores y dinámicas no tiene ya la capacidad de definir la estructura del sistema internacional en términos tanto de capacidad material como de instituciones o ideas. La agenda del desarrollo siempre ha sido una arena contestada y disputada, pero EEUU ya no tiene el papel que tuvo antaño a la hora de definir sus normas y prioridades.

La agenda global del desarrollo ha evolucionado, en gran medida, de acuerdo con la configuración del orden internacional. La crisis de la globalización como orden hegemónico abre posibilidades antes vedadas para el cambio en el sistema internacional de cooperación y ayuda al desarrollo para hacer frente a los desafíos del desarrollo sostenible de manera más inclusiva, legítima y eficaz. Aunque estos apenas se esbozaron con la Declaración del Milenio de 2000, se expresan con mayor claridad en la Agenda 2030 para el Desarrollo Sostenible. Entraron en escena nuevos actores con una capacidad creciente de influencia en la agenda del desarrollo. En este sentido, destacan los países emergentes, protagonistas de las prácticas de cooperación Sur-Sur, las instituciones financieras regionales, así como la sociedad civil.

Gracias a su poder estructural y a su capacidad de agencia, EEUU ha definido durante décadas los regímenes internacionales de ayuda exterior, caracterizados por la securitización, el desvío y la instrumentalización de la ayuda hacia intereses nacionales en los que ha primado una mirada estratégica y de seguridad. Esos intereses nacionales aún están presentes, y son asumidos también, en lógica westfaliana, o "southfaliana", por algunos donantes emergentes. Sin embargo, una globalización en crisis y un orden internacional cuestionado son también una 
oportunidad, en términos de agencia, para nuevos actores y nuevas dinámicas en la ayuda exterior, en una lógica cosmopolita, con el multilateralismo, el desarrollo, el enfoque de derechos y la sostenibilidad como principios rectores para movilizar la acción colectiva frente a riesgos y problemas globales que redefinen el desarrollo como un verdadero desafío existencial para la humanidad.

\section{Anexos}

Anexo I. Principales receptores de la AOD neta desembolsada por EEUU (1960-2019) (millones de dólares a precios constantes)

\begin{tabular}{|c|c|c|c|c|c|}
\hline \multirow[b]{2}{*}{ Etapa } & \multicolumn{5}{|c|}{ Posición en el ranking y montos de los receptores de AOD } \\
\hline & 1 & 2 & 3 & 4 & 5 \\
\hline \multirow{2}{*}{ 1960-1969 } & India & Vietnam & Pakistán & Corea & Brasil \\
\hline & 41.000 & 19.000 & 18.000 & 13.000 & 11.000 \\
\hline \multirow{2}{*}{ 1970-1979 } & Israel & Vietnam & India & Egipto & Indonesia \\
\hline & 14.000 & 12.000 & 8.000 & 6.000 & 6.000 \\
\hline \multirow{2}{*}{ 1980-1989 } & Israel & Egipto & El Salvador & Bangladesh & $\begin{array}{l}\text { Islas Mariana } \\
\text { del Norte }\end{array}$ \\
\hline & 26.000 & 22.000 & 5.000 & 3.000 & 3.000 \\
\hline \multirow{2}{*}{ 1990-1999 } & Egipto & Israel & Haití & El Salvador & Filipinas \\
\hline & 20.000 & 16.000 & 2.000 & 2.000 & 2.000 \\
\hline \multirow{2}{*}{ 2000-2009 } & Irak & Afganistán & Egipto & Colombia & Sudán \\
\hline & 37.000 & 14.000 & 7.000 & 6.000 & 6.000 \\
\hline \multirow{2}{*}{ 2010-2019 } & Afganistán & Etiopía & Jordania & Kenia & Pakistán \\
\hline & 21.000 & 8.000 & 8.000 & 8.000 & 8.000 \\
\hline
\end{tabular}

Fuente: elaboración propia a partir de datos de la OCDE (2021 a). 
Anexo II. Evolución de la AOD neta desembolsada por EEUU (1960-2019) (millones de dólares a precios constantes)

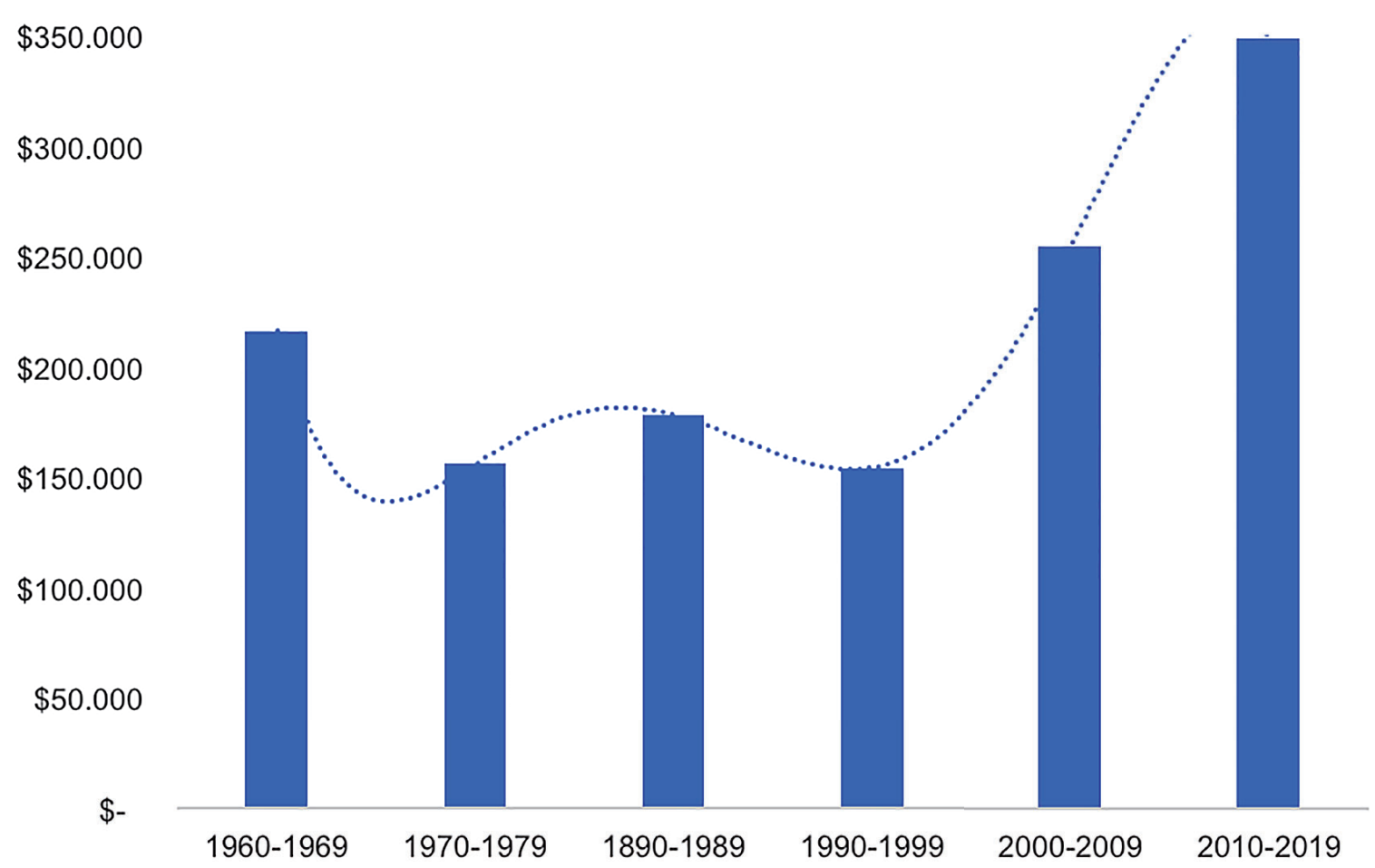

Cifras totales para el periodo mencionado.

Fuente: elaboración propia a partir de datos de la OCDE (2021b). 
Anexo III. Evolución comparada de la AOD neta bilateral y multilateral desembolsada por EEUU (1960-2019) (millones de dólares a precios constantes)

$\$ 300.000$

$\$ 250.000$

$\$ 200.000$

$\$ 150.000$

$\$ 100.000$

$\$ 50.000$

$\$-$
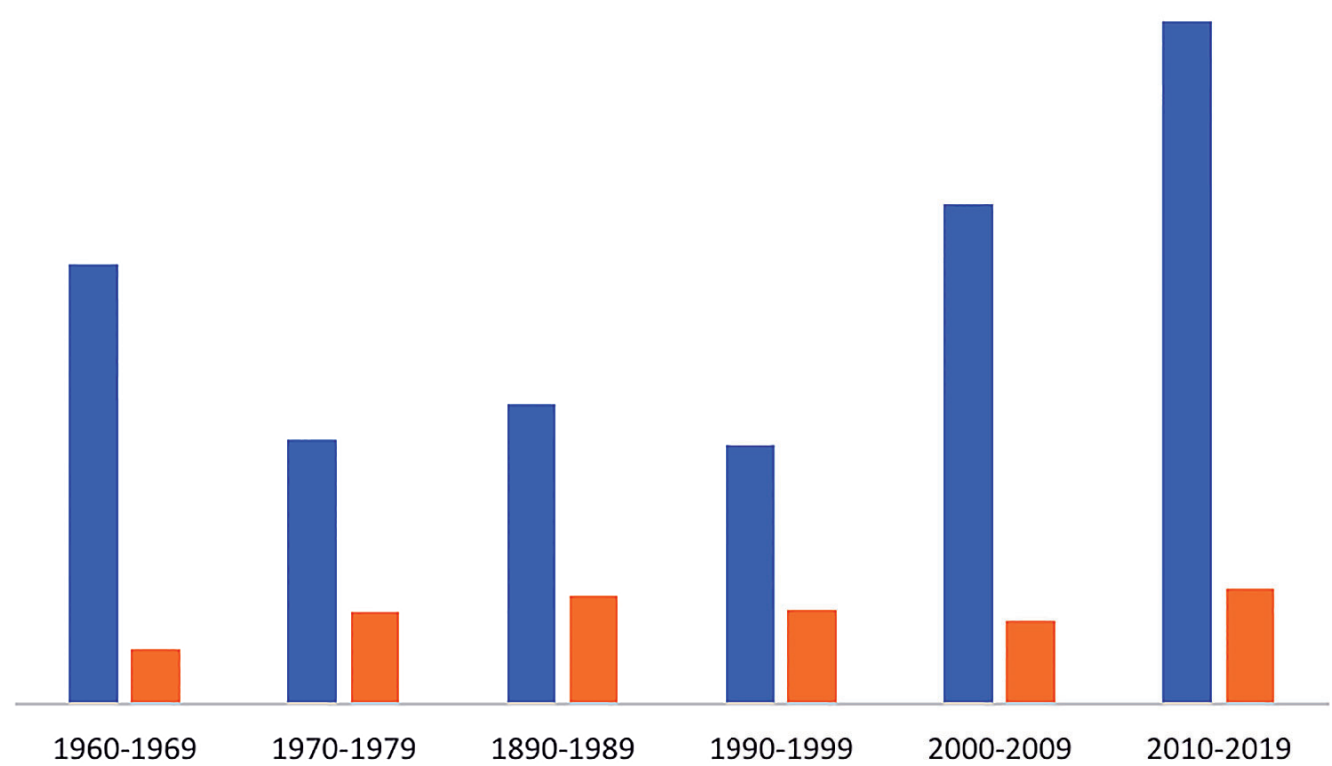

-Bilateral $\square$ Multilateral

Fuente: elaboración propia a partir de datos de la OCDE (2021b).

\section{Bibliografía}

Bello, W., Cunningham, S. y Rau, B. (1994). Dark Victory: The United States, Structural Adjustment and Global Poverty, Pluto / Transnational Institute.

Bergamaschi, I. y TiCKNer, A. B. (2017). "Introduction: South-South Cooperation Beyond the Myths-A Critical Analysis", en I. BergamasCHI, P. MOORE y A. B. TiCKNeR (Eds), South-South Cooperation Beyond the Myths. Rising Donors, New Aid Practices?, 1-27, Palgrave Macmillan.

Booth, K. (2013). "Seguridad y emancipación". Relaciones Internacionales, 23, 99-116.

BroWN, S. y GrÄVINGHOLt, J. (2016). "Security, Development and the Securitization of Foreign Aid", en S. BROWN Y J. GRÄVINGHOLt (Eds.), The Securitization of Foreign Aid, 1-17, Palgrave Macmillan. 
BROWN, S., GRÄVINGHOLt, J. y RadDATZ, R. (2016). "The Securitization of Foreign Aid: Trends, Explanations and Prospects", en S. Brown y J. GräVINGHOLt (Eds.), The Securitization of Foreign Aid, 237-255, Palgrave Macmillan.

Cardoso, F. E. y Faletto, E. (1971). Dependencia y Desarrollo en América Latina. Siglo XXI Editores.

ChaturvedI, S. et al. (2021). "Development Cooperation in the Context of Contested Global Governance", en S. ChATURVED ET AL. (Eds.), The Palgrave Handbook of Development Cooperation for Achieving the 2030 Agenda, 1-21, Palgrave Macmillan.

Chenery, H. y Strout, A. M. (1966). "Foreign Assistance and Economic Development". The American Economic Review, 56 (4), 680-773.

ChRISTOPHER, W. (1995). "America's Leadership, America's Opportunity", Foreign Policy, 98, 6-27.

Cox, R. (1981). "Social Forces, States and World Orders: Beyond International Relations Theory", Millennium: Journal of International Studies (10) 2, 126-155.

EscobAR, A. (1995). Encountering Development: The Making and Unmaking of the Third world. Princeton University Press.

Esteva, G. (1996). "Desarrollo", en W. SACHS (Ed.), Diccionario del desarrollo. Una guía del conocimiento como poder, 52-78, PRATEC.

Esteves, P. y KuInGebieL, S. (2021). "Diffusion, Fusion, and Confusion: Development Cooperation in a Multiplex World Order", en S. Chaturvedi et al. (Eds.), The Palgrave Handbook of Development Cooperation for Achieving the 2030 Agenda, 185-215, Palgrave Macmillan.

FurIA, A. (2015). The Foreign Aid Regime. Gift-Giving, States and Global Dis/ Order, Palgrave Pivot.

Fourie, E., Nauta, W. y Mawdsley, E. (2019). "Introduction", en E. Mawdsley, E. FOURIE, y W. NAUTA (Eds.), Researching South-South development cooperation: The politics of knowledge production, 1-11, Routledge.

GADDIS, J. L. (1982). Strategies of Containment: A Critical Appraisal of Postwar American National Security Policy, Oxford University Press. 
GrifFIN, K. (1994). "Foreign Aid after the Cold War". Development and Change, $22,645-685$.

GrifFIN, K. y MCKINLEY, T. (1994). Implementing a Human Development Strategy, Macmillan.

GRIFITH-JONES, S. (1988). "La condicionalidad cruzada o la expansión del ajuste obligatorio". Pensamiento Iberoamericano, 13, 67-90

Gronemeyer, M. (1996). "Ayuda". En W. Sachs (Ed.), Diccionario del desarrollo. Una guía del conocimiento como poder, 8-31, PRATEC.

HALIDAY, F. (1983). The Making of the Second Cold War, Verso.

Harbone, B. (2012). "Aid: A Security Perspective", en J. Spear y P. Willams (Eds.), Security and Development in Global Politics: A Critical Comparison, 37-56, Georgetown University Press.

HetTNe, B. y Blomström, M. (1990). Teoría del desarrollo en transición, Fondo de Cultura Económica.

KALDOR, M. (2005). La sociedad civil global: una respuesta a la guerra, Tusquets.

KRASNER, S. (1982). "Structural causes and regime consequences: regimes as intervening variables", International Organization, 36 (2), 185-205.

LAfEBer, W. (1989). Revoluciones inevitables. La política de Estaos Unidos en Centroamérica, Universidad Centroamericana (UCA)

LEVINSON, J. y DE ONís, J. (1972). La alianza extraviada. Un informe crítico sobre la Alianza para el Progreso, Fondo de Cultura Económica

LUMSDAINE, D. (1993). Moral vision in international politics: the foreign aid regime, 1949-1989, Princeton University Press.

MarShall, G. (1947). Marshall Plan Speech. The George Marshall Foundation. Acceso 6 de junio de 2020. Disponible en: https://www.marshallfoundation.org/ library/digital-archive/marshall-plan-speech-original/

Messina, A. M. (2014). "Securitizing immigration in the age of terror", World Politics, 66 (3), 530-559. 
Morgenthau, H. (1962). "A Political Theory of Foreign Aid", The American Political Science Review, 56 (2), 301-309.

Keohane, R. y Nye, J. (1977). Power and interdependence. World Politics in Transition, Little, Brown.

LAKE, A. (1993). "From Containment to Enlargement", Dispatch, 4 (39), 658-666.

Mawdsley, E., Murray, W. E., Overton, J., Scheyvens, R., y Banks, G. (2018). "Exporting stimulus and "shared prosperity": Reinventing foreign aid for a retroliberal era", Development Policy Review, 36 (S1), O25-O43.

MCNeILL, D. (2019). "The contested discourse of sustainable agriculture", Global Policy, 10 (S1), 16-27.

OCDE (2021 a). Aid (ODA) disbursements to countries and regions [DAC2a]. Acceso 8 de junio de 2021. Disponible en: https://stats.oecd.org/Index.aspx?ThemeTreeld=3

OCDE (2021b). Total flows by donor [DAC1]. Acceso 9 de junio de 2021. Disponible en: https://stats.oecd.org/Index.aspx?ThemeTreeld=3

PaCKenham, R. (1973). Liberal America and the Third World, Princeton University Press.

Pearson, L. (1969). Partners in Development. Report of the Commission on International Development, Praeger.

PNUD (1990). Informe de Desarrollo Humano. 1990, Tercer Mundo Editores. Acceso 3 de junio de 2021. Disponible en: http://hdr.undp.org/sites/default/files/ hdr_1990_es_completo_nostats.pdf

Raffert, K. y Singer, H. W. (1996). The Foreign Aid Business. Economic Assistance and Development Cooperation, Edward Elgar.

RIDDELL, R. (1987). Foreign Aid Reconsidered, Overseas Development Institute / The John Hopkins University Press.

RIST, G. (2002). El Desarrollo: historia de una creencia occidental, La Catarata.

ROSENAU, J. S. (1991). Turbulence in world politics. A Theory of change and continuity, Princeton University Press. 
ROSENSTEIN-RodAN, P. N. (1944). "The International Development of Economically Backward Areas", International Affairs (Royal Institute of International Affairs), 20 (2), 157-165.

ROSNER, J. (1998). "American Assistance to the Former Soviet States in 1993-1994", en J. M. Scom (Ed.), After the End: Making US Foreign Policy in the Post-Cold War World, 225-250, Duke University Press.

Rostow, W. (1960). The Stages of Economic Growth. A non-Communist Manifesto, Cambridge University Press

SACHS, G. (1996). "Introducción", en W. SACHS (Ed.), Diccionario del desarrollo. Una guía del conocimiento como poder, 1-7, PRATEC.

SanAHUja, J. A. (1999). Ayuda económica y seguridad nacional. La ayuda externa de Estados Unidos, del Plan Marshall a la posguerra fría, Entinema.

- (2001a). Altruismo, mercado y poder. El Banco Mundial y la lucha contra la pobreza, Intermón Oxfam.

- (2001b). "Del interés nacional a la ciudadanía global: la ayuda al desarrollo y las transformaciones de la sociedad internacional", en J. A. SANAHUja y M. GómeZ GALÁN (Coords.), La cooperación al desarrollo en un mundo en cambio: perspectivas sobre nuevos ámbitos de intervención, 53-127, CIDEAL.

- (2011). "Entre los Objetivos de Desarrollo del Milenio y la cooperación sursur: actores y políticas de la ayuda al desarrollo en América Latina y el Caribe". Pensamiento Iberoamericano, 8, 195-222.

- (2016). "Entre Westfalia, Southfalia y Cosmópolis: la gobernanza global del desarrollo sostenible en el horizonte 2030", en GarCíA SegurA. C. (Coord.), La tensión cosmopolita. Avances y límites en la institucionalización del cosmopolitismo, Tecnos, 243-290

- (2017). "Posglobalización y ascenso de la extrema derecha: crisis de hegemonía y riesgos sistémicos". En M. Mesa (Coord.), Seguridad internacional y democracia: guerras, militarización y fronteras. Anuario CEIPAZ 2016-2017, 41-77, CEIPAZ.

- (2019). "Hegemonía, crisis de globalización y Relaciones Internacionales. Concepciones clásicas y teorización crítica", en GonzÁLEz, P. (ed.) El sistema in- 
ternacional del siglo XXI. Dinámicas, actores y relaciones internacionales, Tirant lo Blanch, 19-51.

Sanahuja, J. A. y SChÜnemann, J. (2012). "El nexo seguridad-desarrollo: entre la construcción e la paz y la securitización de la ayuda", en J. A. SANAHuJA (Coord.), Construcción de la paz, seguridad y desarrollo. Visiones, políticas y actores, 17-70, UCM.

SEN, A. (1989). "Development as Capability Expansion", Journal of Development Planning, 19, 41-58.

SeverINO, J. M. y RAY, O. (2009). "The end of ODA: Death and rebirth of a global public policy", Working Paper 167, Center for Global Development.

SPEAR, J. (2016). "The militarization of United States Foreign Aid", en S. Brown y J. GrÄVINGHOLt (Eds.), The Securitization of Foreign Aid, 18-41, Palgrave Macmillan.

StRANGe, S. (1994). States and Markets, Pinter.

StREeTEN, P. (1986). Lo primero es lo primero. Satisfacer las necesidades humanas básicas en los países en desarrollo, Tecnos, Banco Mundial.

VALCÁRCEL, M. (2006). Génesis y evolución del concepto y enfoques sobre el desarrollo. Documento de investigación. Pontificia Universidad Católica del Perú. Acceso 1 de junio de 2021. Disponible en: https://www.uv.mx/mie/files/2012/10/ SESION-6-Marcel-Valcarcel-Desarrollo-Sesion6.pdf

TRUMAN, H. S. (1949). Inaugural Address of Harry S. Truman. Acceso 29 de mayo de 2021. Disponible en: https://avalon.law.yale.edu/20th_century/truman.asp

Waever, O., Buzan, B. y De Wilde, J. (1998). Security: A new Framework for Analysis, Lynne Riener.

WiLlamson, J. (1990). Latin American Adjustment. How much has happened? Institute for International Economics. 